\title{
Prevalence and pattern of dyslipidemia in an Egyptian children and adolescents with type 1 diabetes
}

Hend Soliman ${ }^{*}$ and Amany Ibrahim(D)

\begin{abstract}
Background: Hyperglycemia and dyslipidemia are commonly found metabolic abnormalities in diabetic children and adolescents and both increase the risk of cardiovascular disease. This study aimed to assess the prevalence and the pattern of dyslipidemia in Egyptian children and adolescents with type 1 diabetes (T1DM) and determine its relation with the glycemic control.

Results: This retrospective study included 806 children and adolescents with T1DM; 358 (44.42\%) males and 448 (55.58\%) females. Their mean age was $11.71 \pm 3.6$ years. Clinical and laboratory data were recruited from patients' files. Laboratory data include the most recent fasting lipid profile (triglycerides (TG), total cholesterol $(T C)$, high-density lipoprotein (HDL) and low-density lipoprotein (LDL)), and the mean glycosylated hemoglobin ( $\mathrm{HbA} 1 \mathrm{c})$ levels over the preceding year presented in percentage were calculated. Dyslipidemia in children and adolescents with T1DM represented 70.47\% (568 patients). No statistically significant differences were detected between patients with and without dyslipidemia. As regards the pattern of dyslipidemia, high LDL and low HDL were the most frequent abnormalities in the study group; $62.16 \%, 60.21 \%$, respectively. Patients with poor glycemic control ( $\mathrm{HbA} 1 \mathrm{c}>7.5 \%)$ represent $73.45 \%$ and they were significantly older, with longer diabetes duration and higher TC, TG, and LDL compared to patients with good glycemic control. Significant positive correlations were found between $\mathrm{HbA1C}, \mathrm{TG}, \mathrm{TC}$, and LDL with the age and diabetes duration.

Conclusion: We detected high prevalence of dyslipidemia in children and adolescents with T1DM. Therefore, dyslipidemia should be screened for in earlier ages in Egyptian children and adolescents suffering from T1DM. Programs directed to the prevention of dyslipidemia should be conducted, particularly for this group, in order to prevent/delay cardiovascular complications related to dyslipidemia. Also, parents should receive proper education targeting the prevention, control, and care of their diabetic children with dyslipidemia.
\end{abstract}

Keywords: Type 1 diabetes, Dyslipidemia, Cardiovascular disease, Glycemic control

\footnotetext{
*Correspondence: ziad.alaa@yahoo.com

The work was a retrospective study performed at the outpatient clinic of The

Diabetes Endocrine and Metabolism Pediatric Unit (DEMPU), Children's

Hospital, Cairo University, Cairo, Egypt.

The Diabetes Endocrine and Metabolism Pediatric Unit (DEMPU), Pediatric

Department, Faculty of Medicine, Cairo University, Cairo, Egypt
}

\section{Springer Open}

(๑) The Author(s). 2021 Open Access This article is licensed under a Creative Commons Attribution 4.0 International License, which permits use, sharing, adaptation, distribution and reproduction in any medium or format, as long as you give appropriate credit to the original author(s) and the source, provide a link to the Creative Commons licence, and indicate if changes were made. The images or other third party material in this article are included in the article's Creative Commons licence, unless indicated otherwise in a credit line to the material. If material is not included in the article's Creative Commons licence and your intended use is not permitted by statutory regulation or exceeds the permitted use, you will need to obtain permission directly from the copyright holder. To view a copy of this licence, visit http://creativecommons.org/licenses/by/4.0/. 


\section{Background}

Type 1 diabetes mellitus (T1DM) is one of the most common endocrine disorders in children and adolescents. It has been estimated to affect about 3\% of children around the world [1]. Hyperglycemia and dyslipidemia are metabolic abnormalities commonly found in children and adolescents with T1DM and both increase the risk of cardiovascular disease (CVD) [2]. The prevalence of dyslipidemia is continuously increasing worldwide probably due to Westernization of diet, sedentary lifestyle, reduced physical activity, and urbanization as well as obesity [3].

HDL levels in T1DM are commonly reported to be higher than those detected in the general population, although CVD risks in this patient group are considerably high. It has been demonstrated that the HDL has the capacity to transform from a protective antiinflammatory molecule to a dysfunctional proinflammatory equivalent in the presence chronic illness [4]. This effect could be attributed to factors as systemic inflammation [5] or renal dysfunction [6] and can lead to reversal of the well-documented inverse relationship between serum HDL levels and adverse CVD outcomes [7]. Also, hypertriglyceridemia occurs in T1DM. Moreover, patients with diabetes show qualitative and kinetic abnormalities for all lipoproteins. Many factors may explain to the changes in lipid metabolism observed in T1DM patients, including insulin deficiency or even resistance, adipocytokines, and hyperglycemia due to poor glycemic control. Insulin deficiency or resistance stimulates an intracellular lipase that in turn increases the secretion of non-esterified fatty acids (NEFA) from triglycerides (TG) stored in the active central adipose tissue. High levels of NEFA in the circulation increase hepatic TG production which results in increased secretion of apolipoprotein B (apoB). Additionally, the normal inhibitory effect of insulin on hepatic apoB production and TG secretion in very lowdensity lipoproteins (VLDL) is lost, because the liver cannot respond to increased NEFA flux under severe insulin deficiency; therefore, VLDL secreted becomes larger and more TG-rich. This hypertriglyceridemia is further increased by reduced VLDL catabolism [8]. Lipoprotein lipase found on vascular endothelium largely determines the rate of degradation of TG from the circulation. In contrast to intracellular lipase, this vascular lipoprotein lipase is downregulated by either insulin resistance or deficiency. This decrease in lipoprotein lipase activity also results in postprandial lipemia. Thus, hypertriglyceridemia in patients with T1DM is mainly due to defective removal of TG. This mechanism provides essential knowledge for understanding hypertriglyceridemia occurring in T1DM patients [9].
Atherosclerosis can occur earlier in life in patients with T1DM, leading to increased morbidity and mortality compared with the general population [10]. Dyslipidemia increases the frequency and severity of micro and macrovascular complications of T1DM and is responsible for about 4.4 million deaths worldwide [11, 12]. Atherogenic dyslipidemia is one of the major and modifiable risk factors for CVD and its related mortality in diabetic patients [3]. Moreover, an association between elevated glycosylated hemoglobin (HbA1c) and serum lipid levels has been reported [10]. The aim of the study is to assess the prevalence and the pattern of dyslipidemia in Egyptian children and adolescents with T1DM and determine its relation with the glycemic control.

\section{Methods}

\section{Study population}

This retrospective study included 806 children and adolescents (1-18 years), at least 1-year diabetes duration. Patients with other autoimmune or chronic conditions condition or taking drugs that may affect the lipid profile were excluded. All the patients were not using any medication except insulin. Data of the patients were collected from patients' files during the period from March to December 2017.

Patients were classified based on their lipid profile into 2 groups: dyslipidemia and normo-lipidemia groups and comparison was done between the 2 groups. We were unable to assess puberty and family history of CVD due to limitations in the medical records.

\section{Data collection}

The data were extracted from the medical records of the children and adolescents with T1DM. Diabetes mellitus was diagnosed according to the American Diabetes Association (ADA) criteria which takes into consideration typical clinical symptoms of diabetes, such as polyuria and polydipsia, usually non-obese with no signs of insulin resistance, may present with diabetic ketoacidosis, and requiring insulin from the onset of disease, and the following laboratory findings: random plasma glucose > $11.1 \mathrm{mmol} / \mathrm{L}$, fasting plasma glucose $>7.0 \mathrm{mmol} / \mathrm{L}$, or glycated hemoglobin (HbA1C) > 6.5\% [13].

Patients' anthropometric data including height, weight, and BMI were plotted on Egyptian growth curves [14]. Children were defined as overweight or obese if their BMI was equal to or above 85th percentile and above 95th percentile respectively and both groups were excluded from out study. Growth vision computer software provided by Novo Nordisk, Denmark, was employed to assess height SDS (standard deviation score), weight SDS, and BMI SDS.

Data also included the current age, gender, age of diagnosis of T1DM, diabetes duration in addition to the 
most recent laboratory data including fasting lipid profile (triglycerides (TG), and total cholesterol (TC), highdensity lipoprotein (HDL), and low-density lipoprotein (LDL). Mean glycosylated hemoglobin (HbA1c) levels over the preceding year presented in percentage were calculated. All children and adolescents with T1DM received similar diabetes, nutrition, physical activity counseling, and insulin treatment (basal-bolus regimen (multiple daily injections)) as per department protocol. Total daily insulin dose per kilogram was calculated (U/ $\mathrm{kg} /$ day). Secondary hyperlipidemia from thyroid disorders, renal, and liver diseases were excluded.

Dyslipidemia was defined as having low-density lipoprotein-cholesterol (LDL) $\geq 100 \mathrm{mg} / \mathrm{dl}$, high-density lipoprotein-cholesterol (HDL) $<40 \mathrm{mg} / \mathrm{dl}$ (males), and < $50 \mathrm{mg} / \mathrm{dl}$ (females), total cholesterol (TC) $\geq 200 \mathrm{mg} / \mathrm{dl}$, and triglycerides (TG) $\geq 150 \mathrm{mg} / \mathrm{dl}$ according to ADA definition, and dyslipidemia is present if one or more of these lipid or lipoprotein levels are abnormal [15].

\section{Statistical analysis}

All data were tabulated and analyzed using the Statistical Package for Social Science (SPSS version 22). The data were presented as number and percentages for the qualitative data, mean, standard deviations and ranges for the quantitative data with parametric distribution and median with inter quartile range (IQR) for the quantitative data with non- parametric distribution. Chi-square test was used in the comparison between two groups with qualitative data. Independent $t$ test was used in the comparison between two groups with quantitative data and parametric distribution and Mann-Whitney test was used in the comparison between two groups with quantitative data and non-parametric distribution. $P$ values $<0.05$ were considered statistically significant.

\section{Results}

The study group included 806 children and adolescents with T1DM; 358 (44.42\%) males and 448 (55.58\%) females. Their mean age was $11.71 \pm 3.6$ years. Females had significantly high TG compared to males; however, there was not any other statistically significant differences between them (Table 1).

Dyslipidemia in children and adolescents with T1DM represented $70.47 \%$ (568 patients). Age, sex, diabetes duration, age of diabetes onset, HbA1c, diabetes control, and anthropometric data did not show any statistically significant differences between patients with and without dyslipidemia, and only the lipid profile (TG, LDL, TC, HDL) showed significant differences between the compared groups (Table 2). As regards the pattern of dyslipidemia, high LDL and low HDL were the most frequent abnormalities in the study group; $62.16 \%, 60.21$ respectively (Fig. 1).

Patients with poor glycemic control (HbAlc > 7.5\%) represent $73.45 \%$ and they were significantly older, with longer diabetes duration and higher TC, TG, and LDL compared to patients with good glycemic control (Table 3).

There were significant positive correlations between HbA1c, TG, TC, and LDL with the age, and diabetes duration (Table 4).

\section{Discussion}

Diabetes is one of the predisposing agents for dyslipidemia and atherosclerosis, and there are evidences which show atherosclerosis even begins at childhood [9]. Moreover, the risk of coronary artery disease (CAD) is 2-4

Table 1 Demographic and laboratory characteristics of the study group by gender

\begin{tabular}{|c|c|c|c|}
\hline & Males $(n=358)$ & Females $(n=448)$ & $P$ value \\
\hline Age (years), median (range) & $11.8(2.8-17.7)$ & $12.3(2.6-18)$ & 0.14 \\
\hline Age of diabetes onset (years), median (range) & $6(1-15.1)$ & $6.4(1-15)$ & 0.34 \\
\hline Diabetes duration (years), median (range) & $5(1-17)$ & $5(1-15.2)$ & 0.58 \\
\hline Insulin dose (U/kg/day), mean $\pm S D$ & $1.3 \pm 0.7$ & $1.2 \pm 0.8$ & 0.06 \\
\hline Weight SDS, mean \pm SD & $-0.8 \pm 1.3$ & $-0.7 \pm 1.1$ & 0.23 \\
\hline Height SDS, mean \pm SD & $-1.25 \pm 1.3$ & $-1.43 \pm 1.4$ & 0.06 \\
\hline BMI SDS, mean \pm SD & $-0.8 \pm 1.21$ & $-1 \pm 1.7$ & 0.06 \\
\hline $\mathrm{TC}(\mathrm{mg} / \mathrm{dl})$, mean $\pm \mathrm{SD}$ & $153.57 \pm 45.23$ & $158.71 \pm 45.38$ & 0.12 \\
\hline $\mathrm{TG}(\mathrm{mg} / \mathrm{dl})$, mean $\pm \mathrm{SD}$ & $80.6 \pm 39.73$ & $86.39 \pm 36.94$ & $0.03^{*}$ \\
\hline $\mathrm{LDL}(\mathrm{mg} / \mathrm{dl})$, mean $\pm \mathrm{SD}$ & $96.57 \pm 32.41$ & $98.73 \pm 31.96$ & 0.35 \\
\hline $\mathrm{HDL}(\mathrm{mg} / \mathrm{dl})$, mean $\pm \mathrm{SD}$ & $51.24 \pm 16.1$ & $52.25 \pm 19.78$ & 0.43 \\
\hline $\mathrm{HbA1c}(\%)$, mean $\pm \mathrm{SD}$ & $8.75 \pm 1.77$ & $8.75 \pm 1.81$ & 0.97 \\
\hline Dyslipidemia, frequency (\%) & $243(67.88 \%)$ & 325 (72.54\%) & 0.15 \\
\hline
\end{tabular}

${ }^{*} P$ value $<0.05$ is considered significant, $T C$ total cholesterol, TG triglycerides, $L D L$ low-density lipoprotein, $H D L$ high-density lipoprotein, $H b A 1 c$ glycosylated hemoglobin, BMI body mass index, SDS standard deviation score 
Table 2 Demographic and laboratory data of patients with and without dyslipidemia

\begin{tabular}{|c|c|c|c|}
\hline & Dyslipidemia $(n=568)$ & Normo-lipidemia $(n=238)$ & $P$ value \\
\hline Age (years), median (range) & $12.1(2.6-18)$ & $12(3-17.7)$ & 0.29 \\
\hline \multicolumn{4}{|l|}{ Sex } \\
\hline - Male & $243(42.78 \%)$ & $115(48.32 \%)$ & \multirow[t]{2}{*}{0.15} \\
\hline - Female & $325(57.22 \%)$ & $123(51.68 \%)$ & \\
\hline Age of diabetes onset (years), median (range) & $6.1(1-15)$ & $6(1-15.1)$ & 0.75 \\
\hline Diabetes duration (years), median (range) & $5(1-17)$ & $5(1-15)$ & 0.08 \\
\hline Insulin dose (U/kg/day), mean $\pm \mathrm{SD}$ & $1.1 \pm 0.7$ & $1.2 \pm 0.67$ & 0.06 \\
\hline Weight SDS, mean \pm SD & $-0.7 \pm 1.4$ & $-0.89 \pm 1.3$ & 0.07 \\
\hline Height SDS, mean \pm SD & $-1.53 \pm 1.6$ & $-1.62 \pm 1.4$ & 0.45 \\
\hline BMI SDS, mean \pm SD & $-0.56 \pm 1$ & $-0.7 \pm 1.2$ & 0.08 \\
\hline $\mathrm{TC}(\mathrm{mg} / \mathrm{dl})$, mean $\pm \mathrm{SD}$ & $167.96 \pm 75.8$ & $128.75 \pm 29.71$ & $<0.001^{*}$ \\
\hline $\mathrm{TG}(\mathrm{mg} / \mathrm{dl})$, mean $\pm \mathrm{SD}$ & $90.24 \pm 41.42$ & $68.5 \pm 23.25$ & $<0.001^{*}$ \\
\hline $\mathrm{LDL}(\mathrm{mg} / \mathrm{dl})$, mean $\pm \mathrm{SD}$ & $107.69 \pm 31.81$ & $73.94 \pm 16.87$ & $<0.001^{*}$ \\
\hline $\mathrm{HDL}(\mathrm{mg} / \mathrm{dl})$, mean $\pm \mathrm{SD}$ & $48.59 \pm 18.45$ & $59.53 \pm 15.1$ & $<0.001^{*}$ \\
\hline $\mathrm{HbA} 1 \mathrm{c}(\%)$, mean $\pm \mathrm{SD}$ & $8.79 \pm 1.77$ & $8.62 \pm 1.83$ & 0.22 \\
\hline \multicolumn{4}{|l|}{ Glycemic control } \\
\hline Poor & 425 & 167 & \multirow[t]{2}{*}{0.17} \\
\hline Good & 143 & 71 & \\
\hline
\end{tabular}

${ }^{*} P$ value $<0.05$ is considered significant, $T C$ total cholesterol, TG triglycerides, $L D L$ low-density lipoprotein, $H D L$ high-density lipoprotein, $H b A 1 c$ glycosylated hemoglobin, $B M I$ body mass index, SDS standard deviation score

times in diabetic individuals more than normal people [16]. Early diagnosis of raising blood cholesterol levels in asymptomatic individuals enables the recognition of an essential modifiable risk factor for CAD and who may get benefit from more serious dietary interventions [12].
Our study represents retrospective data from a single large diabetes care center in which we found a high prevalence of dyslipidemia $(70.47 \%)$ in children and adolescents with T1DM. This high prevalence has been also reported in many studies [17-20]. However, this

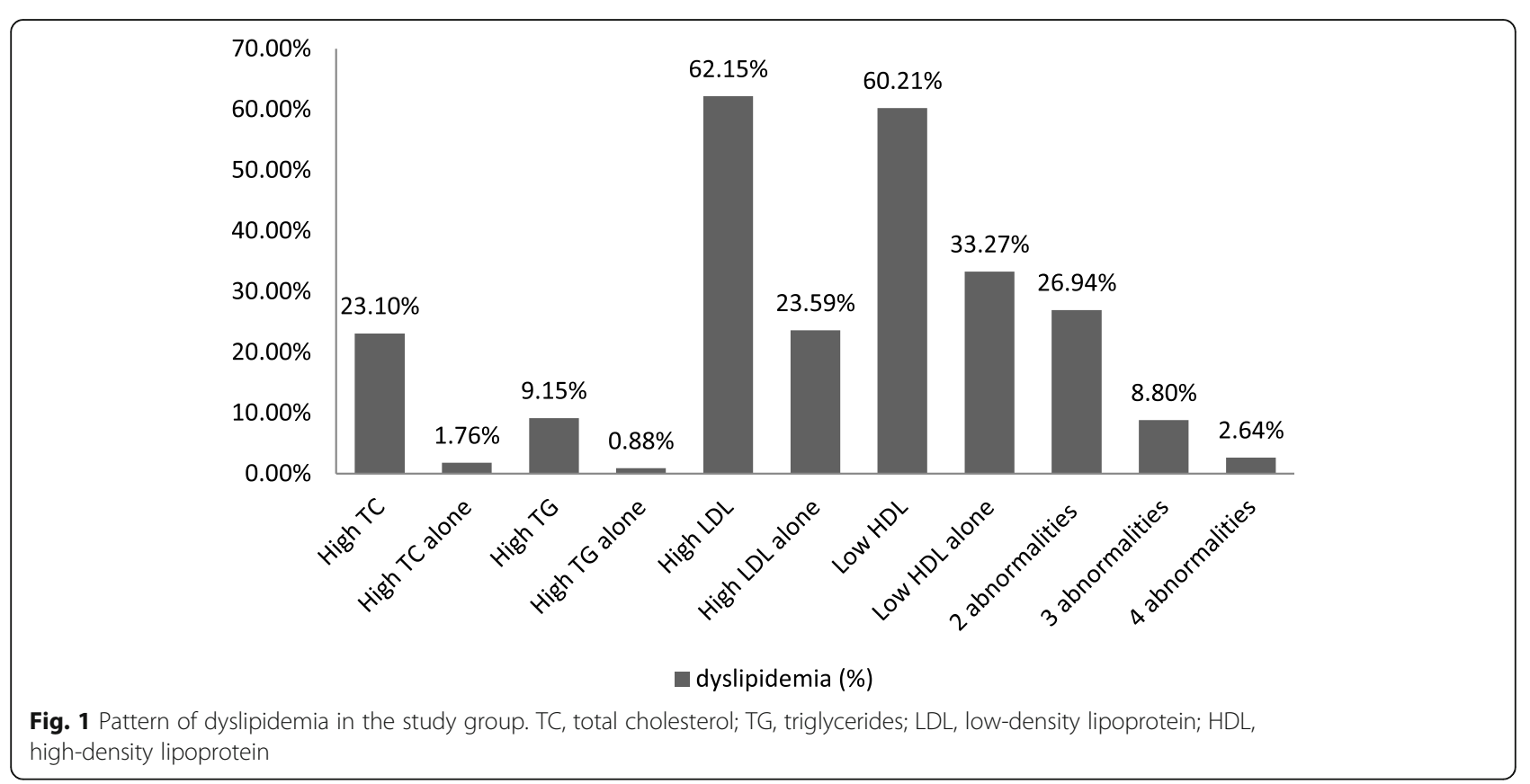


Table 3 Demographic and laboratory characteristics of the study group by glycemic control

\begin{tabular}{|c|c|c|c|}
\hline & Poor glycemic control $(n=592)$ & Good glycemic control $(n=214)$ & $P$ value \\
\hline Age (years), median (range) & $12.4(2.8-18)$ & $11(2.6-17.72)$ & $0.001^{*}$ \\
\hline \multicolumn{4}{|l|}{ Sex } \\
\hline - Male & 260 & 98 & \multirow[t]{2}{*}{0.64} \\
\hline - Female & 332 & 116 & \\
\hline Age of diabetes onset, median (range) & $6.12(1-14.4)$ & $6(1-15.1)$ & 0.36 \\
\hline Diabetes duration (years), median (range) & $5(1-17)$ & $4.8(1-14.7)$ & $0.01^{*}$ \\
\hline Insulin dose $(\mathrm{U} / \mathrm{kg} /$ day), mean $\pm \mathrm{SD}$ & $1.29 \pm 0.41$ & $1.24 \pm 0.32$ & 0.1 \\
\hline Weight SDS, mean \pm SD & $-0.9 \pm 1.4$ & $-0.69 \pm 1.5$ & 0.06 \\
\hline Height SDS, mean \pm SD & $-1.34 \pm 1.2$ & $-1.42 \pm 1.5$ & 0.43 \\
\hline BMI SDS, mean \pm SD & $-0.6 \pm 1.4$ & $-0.8 \pm 1.3$ & 0.06 \\
\hline $\mathrm{TC}(\mathrm{mg} / \mathrm{dl})$, mean $\pm \mathrm{SD}$ & $160.42 \pm 46.51$ & $145.19 \pm 40$ & $<0.001^{*}$ \\
\hline $\mathrm{TG}(\mathrm{mg} / \mathrm{dl})$, mean $\pm \mathrm{SD}$ & $85.7 \pm 39.6$ & $78.61 \pm 34$ & $0.02^{*}$ \\
\hline $\mathrm{LDL}(\mathrm{mg} / \mathrm{dl})$, mean $\pm \mathrm{SD}$ & $99.5 \pm 33.16$ & $93.1 \pm 28.8$ & $0.13^{*}$ \\
\hline $\mathrm{HDL}(\mathrm{mg} / \mathrm{dl})$, mean $\pm \mathrm{SD}$ & $52 \pm 19.2$ & $51.25 \pm 15.25$ & 0.6 \\
\hline $\mathrm{HbA} 1 \mathrm{c}(\%)$, mean $\pm \mathrm{SD}$ & $6.46 \pm 1.52$ & $6.76 \pm 0.58$ & $<0.001^{*}$ \\
\hline Dyslipidemia, frequency (\%) & 425 (71.79 \%) & $143(66.82 \%)$ & 0.17 \\
\hline
\end{tabular}

${ }^{*} P$ value $<0.05$ is considered significant, TC total cholesterol, TG triglycerides, LDL low-density lipoprotein, $H D L$ high-density lipoprotein, $H b A 1 c$ glycosylated hemoglobin, $B M I$ body mass index, SDS standard deviation score

relatively higher than a study done in Bangladesh reporting a prevalence of $64 \%$ [10] and a previous Egyptian study that reported a prevalence of $65 \%$ that was done on 60 children and adolescents [21]. This high prevalence in our study was much higher than that reported by other studies who found a prevalence ranged from 26.2 to $48.5 \%$ [11, 22, 23]. This high prevalence of dyslipidemia among our patients could be attributed to the poor glycemic control as the number and percent of diabetic patients with poor glycemic control was higher than their equivalents of good glycemic control in dyslipidemia patients compared to normo-lipidemic patients but this did not reach statistical significance. Furthermore, the prevalence of dyslipidemias in the general Egyptian population including children and adolescents is high and underdiagnosed (37\% of the Egyptian population) [24].

As regards the pattern of dyslipidemia, high LDL and low HDL were the most frequent abnormalities in the study group. This is in line with many previous studies $[17,21,25,26]$. One study documented that increased TC and LDL were the main abnormalities [15].

Table 4 Correlations between the lipid profile and the demographic parameters and glycemic control

\begin{tabular}{|c|c|c|c|c|c|c|}
\hline & & TC & TG & LDL & $\mathrm{HDL}$ & HbA1c \\
\hline \multirow[t]{2}{*}{ Age of diabetes onset } & Pearson correlation & -0.02 & 0.05 & -0.02 & 0.06 & 0.03 \\
\hline & $P$ value & 0.61 & 0.14 & 0.64 & 0.09 & 0.34 \\
\hline \multirow[t]{2}{*}{ Diabetes duration } & Pearson correlation & 0.24 & 0.08 & 0.12 & 0.05 & 0.2 \\
\hline & $P$ value & $<0.001^{*}$ & $0.02^{*}$ & $0.001^{*}$ & 0.17 & $<0.001^{*}$ \\
\hline \multirow[t]{2}{*}{ Age } & Pearson correlation & 0.17 & 0.11 & 0.08 & 0.09 & 0.18 \\
\hline & $P$ value & $<0.001^{*}$ & $0.002^{*}$ & $0.026^{*}$ & 0.06 & $<0.001^{*}$ \\
\hline \multirow[t]{2}{*}{ BMI } & Pearson correlation & 0.03 & 0.05 & 0.02 & 0.01 & 0.02 \\
\hline & $P$ value & 0.17 & 0.15 & 0.53 & 0.13 & 0.32 \\
\hline \multirow[t]{2}{*}{ Insulin dose } & Pearson correlation & 0.02 & 0.17 & 0.07 & 0.14 & 0.14 \\
\hline & $P$ value & 0.13 & 0.14 & 0.17 & 0.11 & 0.33 \\
\hline \multirow[t]{2}{*}{$\mathrm{HbA1c}$} & Pearson correlation & 0.19 & 0.13 & 0.11 & 0.07 & 1 \\
\hline & $P$ value & $<0.001^{*}$ & $<0.001^{*}$ & $0.001^{*}$ & 0.07 & \\
\hline
\end{tabular}

${ }^{*} P$ value $<0.05$ is considered significant, $T C$ total cholesterol, $T G$ triglycerides, $L D L$ low-density lipoprotein, $H D L$ high-density lipoprotein, $H b A 1 C$ glycosylated hemoglobin, $B M I$ body mass index 
However, some studies found that hypertriglyceridemia was the main disorder [10, 23, 27]. The wide range of prevalence and patterns of dyslipidemia in different studies may be due to multiple genetic factors in different ethnicities.

There were no significant differences in the prevalence of dyslipidemia between males and females. This is in concordance with a study conducted in Iran in 2017 [12]. On the other hand, Homma et al. [17] reported that females had significantly higher dyslipidemia prevalence.

There were no statistically significant differences between patients with and without dyslipidemia regarding age, sex, diabetes duration, age of diabetes onset, HbAlc, and glycemic control. This agreed with Zabeen et al. [10], and Rahbar and Hajian [12]. Nevertheless, another study reported that age, BMI, HbA1c, and poor metabolic control were significantly higher in cases with dyslipidemia [11].

Patients with poor glycemic control represent (HbA1c > 7.5\%) $73.45 \%$ and they had significantly older, with longer diabetes duration, and higher TC, TG, and LDL compared to patients with good glycemic control. In addition, a significant association between HbAlc and the serum lipids was found in this study. This is in concordance with the results reported by other studies [10, $20,28]$. Serum lipids were higher in patients with poor metabolic control, but there was not significant relation between HbA1c, and diabetes duration as reported by one study [23]. However, other authors found no correlation between poor GC and HDL, LDL, TC, or the TG which is different from our results [17]. These results provide evidence that poor glycemic control can be considered a potential modifiable risk factor for dyslipidemia in this patient group.

There were significant positive correlations between HbA1c, TG, TC, and LDL with the age and diabetes duration. Verma et al. [29] found a significant relation between diabetes duration and HbA1c, which had conformity with this study. Another study reported a significant relationship between HbA1c and TG levels but its relationship with disease duration was not significant [12].

The strengths of this study include the large sample size. However, possible confounding variables that may account for the association between poor glycemic control and dyslipidemia were not considered. Patients with poor glycemic control and poor treatment compliance may be the ones who also do not undertake preventive measures as exercise, healthy diet, and strict follow-up. Data of pubertal assessment were not included in the study as this retrospective study depended mainly on data obtained from patients' records which showed deficiency in this aspect and this limited the power to examine the well-known association between the different pubertal stages and dyslipidemia.

\section{Conclusions}

This study demonstrated high prevalence of dyslipidemia among children and adolescents with T1DM. High LDL and low HDL were the most frequent abnormalities in the study group. Longitudinal studies might be needed for early diagnosis and effective treatment of dyslipidemia which is a potential modifiable risk factor of CVD in children and adolescents with T1DM. So, we suggest that dyslipidemia should be screened for in early ages, particularly in Egyptian children and adolescents suffering from T1DM. Also, parents should be educated about the control and care of their diabetic children with dyslipidemia.

\section{Abbreviations \\ ADA: American Diabetes Association; apoB: Apolipoprotein B; CVD: Cardiovascular disease; CAD: Coronary artery disease; GC: Glycemic control; HbA1c: Glycosylated hemoglobin; HDL: High-density lipoproteins; LDL: Low-density lipoproteins; NEFA: Non-esterified fatty acids; T1DM: Type 1 diabetes; TC: Total cholesterol; TG: Triglycerides; VLDL: Very low-density lipoprotein}

\section{Acknowledgements \\ Not applicable.}

\begin{abstract}
Authors' contributions
$\mathrm{HS}$ and $\mathrm{Al}$ conceived and designed the study plan and wrote the manuscript. HS recruited the subjects, processed samples, contributed to acquisition of data, data monitoring and initial data analysis, supervised the final statistical analysis, and reviewed and edited the manuscript. Al initiated the study idea edited initial drafts and contributed to analyzing and presenting data and collated the final draft in consultation with the other coauthor. The authors read and approved the final manuscript.
\end{abstract}

\section{Funding}

This research did not receive any specific grant from any funding agencies in the public, commercial, or not-for-profit sectors.

\section{Availability of data and materials \\ The datasets used and/or analyzed during this study are available from the corresponding author on reasonable request.}

\section{Declarations}

\section{Ethics approval and consent to participate}

The study protocol was approved by the ethical committee of Cairo University Hospital Research Committee. Ethics committee reference number was not available at the time this work was done. A written informed consent was taken from the parents of the study participants. The study and data collection were conformed to all local laws and were compliant with the principles of the Declaration of Helsinki.

\section{Consent for publication}

Not applicable.

\section{Competing interests}

The authors declare that they have no competing interests. 
Received: 11 February 2021 Accepted: 17 August 2021

Published online: 13 September 2021

\section{References}

1. Yang CC, Lin CH, Wang NK, Lai CC, Lo FS et al (2018) Risk factors associated with the development of nephropathy 10 years after diagnosis in Taiwanese children with juvenile-onset type 1 diabetes - a cohort study from the CGJDES. Front Endocrinol (Lausanne) 9:429

2. Donaghue KC, Wadwa RP, Dimeglio LA, Wong TY, Chiarelli F, Marcovecchio ML et al (2014) ISPAD clinical practice consensus guidelines 2014. Microvascular and macrovascular complications in children and adolescents. Pediatr Diabetes 15:257-269

3. Bekele S, Yohannes T, Mohammed AE (2017) Dyslipidemia and associated factors among diabetic patients attending Durame General Hospital in Southern Nations, Nationalities, and People's Region. Diabetes Metab Syndr Obes 10:265-271

4. Chiesa ST, Charakida M, McLoughlin E, Nguyen HC, Georgiopoulos G, Motran L et al (2019) Elevated high-density lipoprotein in adolescents with Type 1 diabetes is associated with endothelial dysfunction in the presence of systemic inflammation. Eur Heart J 40:3559-3566

5. O'Neill F, Riwanto M, Charakida M, Colin S, Manz J, McLoughlin E et al (2015) Structural and functional changes in HDL with low grade and chronic inflammation. Int J Cardiol 188:111-116

6. Shroff R, Speer T, Colin S, Charakida M, Zewinger S, Staels B et al (2014) HDL in children with CKD promotes endothelial dysfunction and an abnormal vascular phenotype. J Am Soc Nephrol 25:2658-2668

7. Zewinger S, Drechsler C, Kleber ME, Dressel A, Riffel J, Triem S et al (2015) Serum amyloid A: high-density lipoproteins interaction and cardiovascular risk. Eur Heart J 36:3007-3016

8. Verges B (2015) Pathophysiology of diabetic dyslipidaemia: where are we? Diabetologia 58:886-899

9. Taskinen MR (2003) Diabetic dyslipidaemia: from basic research to clinical practice. Diabetologia 46:733-749

10. Zabeen B, Balsa AM, Islam N, Parveen M, Nahar J, Azad K (2018) Lipid profile in relation to glycemic control in type 1 diabetes children and adolescents in Bangladesh. Indian J Endocrinol Metab 22(1):89-92

11. Bulut T, Demirel F, Metin A (2017) The prevalence of dyslipidemia and associated factors in children and adolescents with type 1 diabetes. J Pediatr Endocrinol Metab 30(2):181-187

12. Rahbar A, Hajian A (2017) Dyslipidemia frequency and related factors to blood in children suffering from type 1 diabetes. Biomed Res 28 (19):8402 8405.

13. American Diabetes Association (2019) Classification and Diagnosis of Diabetes: Standards of Medical Care in Diabetes-2019. Diabetes Care 42(1): S13-S28

14. Ghali I, Salah N, Hussien F, Erfan M, El-ruby M, Mazen I et al (2008) Egyptian growth curves for infants, children and adolescents. In: Satorio A, JMH B Marazzi N (eds) Crecere nel mondo. Ferring Publisher, Chemin de la Vergognausaz, Switzerland.

15. American Diabetes Association (2018) Cardiovascular disease and risk management: standards of medical care in diabetes-2018. Diabetes Care 41(1):S86-S104

16. Stamler J, Vaccaro O, Neaton JD, Wentworth D, Group MRFITR (1993) Diabetes, other risk factors, and 12-yr cardiovascular mortality for men screened in the Multiple Risk Factor Intervention Trial. Diabetes Care 16: 434-444

17. Homma TK, Endo CM, Saruhashi T, Mori AP, Noronha RM, Monte O et al (2015) Dyslipidemia in young patients with type 1 diabetes mellitus. Arch Endocrinol Metab. 59:215-219

18. Giuliano ICB, Caramelli B (2008) Dislipidemias na infância e na adolescência. Pediatria 29(4):275-285

19. Boni A, Pugliese C, Chiantelli-Cláudio C, Patin RV, Oliveira FLC (2010) Vitaminas antioxidantes e prevenção da arteriosclerose na infância. Rev Paul Pediatr. 28(4):373-380

20. Guy J, Ogden L, Wadwa RP, Hamman RF, Mayer-Davis EJ, Liese AD et al (2009) Lipid and lipoprotein profiles in youth with and without type 1 diabetes: the SEARCH for Diabetes in Youth case-control study. Diabetes Care 32(3):416-420

21. Mona HM, Sahar SA, Hend SM, Nanees AA (2015) Dyslipidemia in type 1 diabetes mellitus: Relation to diabetes duration, glycemic control, body habitus, dietary intake and other epidemiological risk factors. Gaz Egypt Paediatr Assoc. 63(2):63-68

22. Kim SH, Jung IA, Jeon YJ, Cho WK, Cho KS, Park SH et al (2014) Serum lipid profiles and glycemic control in adolescents and young adults with type 1 diabetes mellitus. Ann Pediatr Endocrinol Metab 19:191-196

23. Moayeri H, Oloomi Z (2006) Prevalence of dyslipidemia in children and adolescents with diabetes mellitus type I. Iran J Pediatr 16:171-176

24. Taha HS, Badran HM, Kandil H, Farag N, Oraby A, El-Sharkawy M et al (2021) Egyptian practical guidance in lipid management 2020. Egypt Heart J 73:17

25. Rahma S, Rashid JA, Farage AH (2006) The significance of lipid abnormalities in children with insulin dependent diabetes mellitus. Iraqi Postgrad Med J 5 : 289-294

26. Al-Naama LM, Kadhim M, Al-Aboud MS (2002) Lipid profile in children with insulin dependent diabetes mellitus. J Pak Med Assoc 52:29-34

27. Alrabaty AA, Alnakshabandi AA, Yahya NB (2009) The lipid profile in children with type 1 diabetes mellitus in Erbil governorate. Iraqi Postgrad Med J 8: 344-349

28. Giuffrida FM, Guedes AD, Rocco ER, Mory DB, Dualib P, Matos OS et al (2012) Brazilian Type 1 Diabetes Study Group (BrazDiab1SG). Heterogeneous behavior of lipids according to $\mathrm{HbA} 1 \mathrm{c}$ levels undermines the plausibility of metabolic syndrome in type 1 diabetes: data from a nationwide multicenter survey. Cardiovasc Diabetol 11:156

29. Verma M, Paneri S, Badi P, Raman P (2006) Effect of increasing duration of diabetes mellitus type 2 on glycated hemoglobin and insulin sensitivity. Indian J Clin Biochem 21:142-146

\section{Publisher's Note}

Springer Nature remains neutral with regard to jurisdictional claims in published maps and institutional affiliations.

\section{Submit your manuscript to a SpringerOpen ${ }^{\circ}$ journal and benefit from:}

- Convenient online submission

- Rigorous peer review

- Open access: articles freely available online

High visibility within the field

- Retaining the copyright to your article

Submit your next manuscript at $>$ springeropen.com 